\title{
Media Paradigms and Programmed Code of Values Orientation in Adolescence
}

\author{
Vladeta Radović ${ }^{1}$, Samir Ljajić ${ }^{1}$, Milan Dojčinović ${ }^{1}$ \\ ${ }^{1}$ University of Niš, Faculty of Philosophy, Cirila i Metodija 2, Niš, Serbia
}

\begin{abstract}
Many studies on media show that apart from family, school and peer groups media get imposed as agents of socialization influencing models of behavior, life styles establishment and young people's code of values formation. This research is dedicated to the range of adolescents' interests, i.e. the influence of informative, educational and distractive media contents. The research findings show that the use of television and the internet occupies everyday activities of the subjects in their spare time, and that it remarkably influences their attitudes and code of values formation. Modern media paradigms promote competences over competitions, diminish codes of values and blur the border line between the good and bad, animal and humanistic. The manipulative media features are getting more dynamic, natural and tougher.
\end{abstract}

Keywords - Media, adolescents, socialization, media culture, values system.

\section{Introduction}

Everyday life system permeated by the myriad of information and other media contents has rapidly evolved into the information - communication structure which is constantly programming the society and social processes.

DOI: $10.18421 /$ TEM102-24

https://doi.org/10.18421/TEM102-24

Corresponding author: Samir Ljajić, University of Niš, Faculty of Philosophy, Ćirila i Metodija 2, Niš, Serbia.

Email: ljajics@gmail.com

Received: 17 December 2020.

Revised: 14 April 2021.

Accepted: 22 April 2021.

Published: 27 May 2021.

(c) BY-NC-ND (C) 2021 Vladeta Radović, Samir Ljajić \& Milan Dojčinović; published by UIKTEN. This work is licensed under the Creative Commons AttributionNonCommercial-NoDerivs 4.0 License.

The article is published with Open Access at www.temjournal.com
There is no point to insist on the image of media as an integral part of life, to discuss their influence or power simply because the system has reached the breaking point - the point of intense influence, and has become a purpose for itself. Moreover, mass broadcasting and autonomous media, along with the e-platform and modern creative industries, through production abundance or, to put it more precisely, "through the occupation", establish a new audiovisual cultural matrix, which will determine the development frameworks of the future. Such illustrative examples can be found in almost all areas as in the RIAA research.

\subsection{Formatting the Public by the New Conventions}

Media as an increasingly important part of the social mileu, helped out with the family and the institutions of the formal education system, comprise a "functional-educational triangle" of children and adolescents. However, political and economic crises disrupt the balance since the media take on the role of socialization agents as children spend much of their time online. Thus, the media take precedence from the school when it comes to upbringing, behavior and patterns of behavior. At the same time, some of the researches conducted in Serbia has shown that "combined with long and frequent viewing of violent scenes on television and film, it leads to reduced sensitivity to aggression and human suffering and a negative and frightening perception of the world" [15].

Despite the intensive development dynamics of information and communication technologies, the superior framework of the new media forms and the convergence of the traditional media in the eenvironment, television still remains a dominant media. It is all about its manner of transmitting messages which engages more than four-fifths of the total perception of the human being. Therefore, the phenomenon, as well as the positive or negative influences of a given medium, have become the subject of numerous research studies. Observing the aspect of mediological, and especially deontological disciplines, it would be also irresponsible to neglect research endeavors aimed at a phenomenon that has, for a long time, been centrally positioned in the society of modernity. 
"The idea that the appearance of television marked a change in the social order has become a wellknown word of our time. It is not uncommon to hear the claim that television programs have a direct impact on human behavior"'[9].

Having in mind that the audio-visual medium represents the most dominant and influential generator of paradigms, reality is being formatted by new conventions, which we unconditionally accept because we have seen and heard them, and then, because during countless repetitions, we have got used to new "values".

"Measuring internalization (Heingberg et. al., 1995) is particularly interesting because it assesses the extent to which the values promoted by the media are integrated into a person's worldview structure". For example, respondents were asked to what extent they agreed with the statement - "Appearance is essential if you want to cope in modern society"."A high degree of agreement with this statement indicates the internalization of a certain value" [2].

\subsection{Media Conglomerats and Public Communication}

The conceptual-categorical structure of the phenomenon "medium" is extremely complex, interdependent and permeated with varied elements of different semantic characteristics. It is quite possible that the term "conglomerate" would be quite appropriate for the elementary, descriptive level of the scientific determination of the given concept. The conglomerate of the meaning of the term medium, however, cannot be reduced to some discrete features, or narrow ranges of finality. There is no single feature, thus all of them, without exception, imply communication as the ultimate goal.

"The comunication realm is the social sphere where values and interests of conflicting actors are engaged in struggle and debate to reproduce the social order, to subvert it, or to accomodate new forms resulting from the interaction between the old and the new the past of crystallized domination and the future of alternative projects of human existence..." [1].

Media are present in absolutely all areas of life:

"In addition to their role to inform, they also involve social relations, entertainment, upbringing and education, forming opinions and attitudes, establishing control, criticism, entertainment, schedule of daily obligations, imposing topics for conversation and discussion, setting patterns of behavior" [13].

\subsection{Phenomenon of the Paralel Reality}

The phenomenon, terminologically marked by a combination of the ancient Greek and Latin word has marked the end of the second and the beginning of the third millennium, ushering a completely new chapter in a developmental cycle. Seeing better or further than what is intended for us has always been the subject of myths and legends. However, to see more or understand better one needs prudence, critical thinking and media literacy, as a subtype of the functional literacy.

"The era of constant flow of information, in a society obsessed with the image, has influenced the media to become so aggressive that many prominent political scientists blame them for creating a kind of mediacracy or democracy in which the media, especially television, dictate rules and priorities..." [4].

The television media fundamentally changed civilization at the end of the second millennium and set the framework for further development. Since the time of the magical rites, myths, legends and beliefs, there has purched a desire of people to discern a "parallel" reality.

"Television is a very powerful initiator of change, an indispensable part of the family environment, a faithful companion of growing up during all phases of life. Consequently, numerous research studies are focusing on television, that is, the medium which shapes young people through their contents, influences their way of thinking and behavior on a daily basis " [7].

Assuming a completely new role in the history of human communication, media have finally satisfied the long-standing need of people to see and hear events occurring at the same time, but at different far away places. Some theorists also compare the television medium with natural phenomena. "Television is like water, whenever you turn on the tap, water flows", said famous Orson Welles .

\subsection{Development Possibilities and the Illusion of Development}

In the course of this medium development, the nineteenth century was largely devoted to solving technical problems, starting from photography until the World's Fair in Paris in 1900, when for the first time, a word television was used. The twentieth century was spent trying to make the picture reach everyoone on the Planet, starting modestly, with an experimental broadcasting of the BBC program in 1930, and the first regular broadcasting from the Eiffel Tower, six years later. Over time, television screens became multifunctional, all the way to a fully operational interface. 
"As children's daily lives become ever more heavily mediated, and as the media themselves simultaneously converge and diversify, researchers along with policy-makers and the public are now debating whether 'the digital age' is enhancing or undermining children's rights, with current controversies centring on children's right to privacy online as offline, to information and freedom of expression, and to protection from sexual and aggressive threats variously mediated and amplified by the Internet" [5].

Users' access to social networks and other Internet contents, higher definition, that is image quality that exceeds 3D technology, are just details of the development that was started in the 19th century.

"In the whirlwind of constant changes, it is not uncommon for human abilities to accept and process information to be completely inadequate. And in the pronounced imbalance of the mentioned abilities and appropriate situations, it is also possible to create a huge and grotesque network of the most diverse abuses. We are witnessing such a misinformative structure of the overall information space of the planet" [11].

The truth and the time of wonder have passed by. Until recently, we could not even imagine the development possibilities of the technological range of possibilities, and nowadays the potentials are recognizable. It is becoming increasingly difficult to distinguish between fiction and science. "By expanding the availability of the Internet, especially online printing, as well as the mobile telecommunications devices, we are entering a time of post-television".

"Television news programs are crucial to the informative function of the media. What we usually call professional news selection and professional structuring a news program also means the practical application of some professional and ethical postulates, so based on the attitude of journalists towards this segment, a conclusion can be made about the attitude of journalists towards professionalism as a whole" [8].

Like all previous technological achievements, the future ones will undoubtedly affect everything, i.e. everything we do, everything we are and will ever be. The beginning belongs to changes in the system in all segments, which implies changes in behavior, i.e. habits, attitudes, beliefs, goals, etc. In just a hundred, for the Cosmos, very trifle years, we have changed to such an extent that we have even convinced ourselves that we are developing rapidly. However, in addition to technology, the spirit is also necessary to develop, and we did not succeed in it, quite the contrary!
"The power of media technologies can only be adequately assessed if it finds its rightful place in the history of culture, power and conflict. Media technology analysis is actually an analysis of people's history and media practices" [10].

The century behind us, apart from numerous insanities, has been spent, primarily, on the development of the media. The century we have started, there is every chance, will have to be reserved for the elimination of the strong consequences of media influence on people's mental health.

\subsection{Border Line Between "Values" and "Value" Orientations}

Values are much more general, more positive, and relatively more constant towards objects or ideas that we consider important. These are goals that are desirable, valuable and important to us, and "we can view them as ideals that we strive for" [12]. The meaning of the terms: "value" and "value orientation", in colloquial terms, is frequently equated. However, some authors make a distinction between the given terms. "Research on children and media, particularly in the USA, continues to be dominated by conventional approaches drawn from developmental psychology, social psychology and communication studies. Exponents of these approaches typically ignore or denigrate Cultural Studies, while also taking little account of innovative theoretical developments within their own disciplines" [3].

Values and value orientations also include cognitive, emotional and acting components, and at the same time, they are, for the most part, more abstract categories than the interests. Unlike attitudes, values, i.e. value orientations, are much more general dispositions and always represent a positive and, for a person, very important characteristic of the overall system. Once established, the value system will form a crucial prism of all relationships and perceptions of the world around us.

\subsection{Adolescence and Code of Values Formation}

The period of adolescence includes the decision which values we will choose, which position to take and which norms to adhere to in relation to those personal and social issues that have become most important to us in the period of growing up. It is the very period that a critical attitude towards everything develops, in the intrapersonal and interpersonal communication, ranging from the intimate problems to social issues and the most abstract categories. 
In the most media-developed environments, children receive an average of about 3,000 commercial messages every day. Research shows that children, even though they grow up in a full world advertising only after the age of 12 do they acquire the ability to fully understand advertising messages. [16]

In relation to whether young people are satisfied or not with their social status or their own position, the consequences can be manifested as: radicalism, as a natural property of the young, lack of interest in general social issues or their intimite world of personal interests, or the young may develop various forms of undesirable behavior such as violent, aggressive, or destructive one.

\section{Research Methodology}

The subject of the research determines a methodological framework of the research: problem, that is the subject of the research, goal and tasks, it also sets the hypothetical framework and methodological tools applied, providing more precise parameters on: the techniques, sample and statistical data processing.

\subsection{Subject, Goal and the Tasks of a more Comprehensive Research Study}

The problems of the given research taking a broader approach are comprising primarily: the quantitative scope and qualitative range of the participation of broadcasting media in the everyday life of the young, as well as the numerous roles that such media play in family and social life. The subject of the research is the correlation and numerous covariations of the media and the development of a young person, that is the scope, intensity and quality of influence on the formation of: interests, attitudes, value orientations and patterns of behavior of the young people, aged 14 to 16 . The scope of critical thinking and the attitude of young people towards media contents were also discussed, as well as the importance of media education to enhance their proper development, unlocking and management of their potential. The research is, according to the scope, hypothetical framework and methodological tools, divided into special research units:

- selection criteria and manner of using the media in the traditional and e-environment;

- identification and analysis of attitudes, established under the influence of media paradigms;

- quantification and qualification of the user level: offline and online;

- demarcation and analysis of elements of positive and negative motivation towards the media;
- research of individual and family user habits of the target population;

- selection and evaluation of different segments of program content;

- quantification of media ratings, that is program contents, drawn as a sample and the basis for the analysis of the value orientation of the target population;

- analysis of interests and activities in the category "leisure time",

- qualification of attitude towards school, as the most important factor of the educational process.

The primary goal of the presented part of the broader research study is the scope and intensity of the effective influence of program media contents on the formation of interests and code of value systems formatting, that is programming of value orientations and given behavior patterns of the investigated adolescents.

\subsection{Scientific, Professional and Social Significance of the Research}

The scientific contribution of the given research is the enriching of the body of scientific knowledge about: the scope, intensity and qualitative properties of the influence of media program contents affecting adolescents attitudes and value orientation establishment. It is also possible that the research results will initiate the application of the new approaches to the subject matter, i.e. the complex phenomenology of the mediological and communication domains. The research results explicitly indicate a direct or indirect influence of the media on the process of a value system establishment and adolescence behavior patterns formatting. Some information, obtained by analysing research results, reveals more precisely the attitudes, habits and way of thinking of the target population. The results can also ignite potential, more complex interdisciplinary research and comparative-analytical research studies. The research provides also a direct argumentation of the necessary strategic approach to media phenomenology and arranging the domain of public communication.

\subsection{Hypothetic Research Design Structure}

General hypothesis: Dominant elements of mediatransmitted paradigms, as indirect and direct exogenous variables, are the basic parameters and agents of the process of programming the value orientation of adolescents!

Special hypotheses: 
1. In adolescence, the degree of the value system formation and media influence efficiency are in a direct-proportional correlation;

2. Media paradigms are in a strong, indirect and direct covariant relationship with the coefficient of influence on the adolescents development.

Control hypothesis:

The key elements of the primary and secondary environment influence, in the developmental processes of adolescence, belong to the endogenous variables complex.

\subsection{Research Methods Instruments}

In the ontological domain, conceptual-categorical analysis of the key areas of this research, the nature and axiological correlations of the researched concepts are considered: mass media, adolescence, paradigmatic parameters of public communication, as well as the value orientations and attitudes, i.e. interests. In the operational part, the research techniques applied included a survey, and the instrument for data collection was made in the form of a combined type questionnaire, specially adapted to the given research. The questionnaire covered more than thirty questions, mostly of the closed type. In addition to the Bogardus social distance scale, the following scales were also applied: Thurstone's and Likert's scale of attitudes, with certain elements of scalogram analysis. The paper presents ten tables.

\subsection{Sample and Research Course}

This research is part of a broader research project, and the sample comprised students in the final grades of five primary schools in the urban region and two rural, branches of the primary schools. The sample included 1004 subjects, and the survey was conducted in the presence of teachers and professionals: psychologists, pedagogues or sociologists. Both genders are represented in the research, and the subjects were informed in detail about the goals of the research and their role in it. According to its character, the questionnaire is administered in groups, it is written, anonymous and conducted on a voluntary basis. The data obtained by the survey were analyzed by the SPSS method, according to the set hypotheses and research tasks. The results are shown in following Tables.

\section{Basic Research Guidelines and Research Findings Interpretation}

\subsection{Technical and Social Parameters of the Media Contents Reception and Processing}

It is very difficult to perceive the relationship between the media and adolescents. Therefore, the given research is directed primarily towards the physical, and then the social circumstances in which the target population uses media. The survey ranged from the questions related to technical characteristics such as the number of television sets, or household computers, i.e. whether young people are independently accessing the media, to more complex items such as the research on family habits and general, personal and collective values in a given research domain. A better understanding of the behavior of younger media users required gathering data on their family life and modalities of media participation in the family communication patterns, i.e: how and to what extent household members influence the choice of program content, or the way and manners of media use, which types of program content family members watch together, and to what extent the media and program contents fit into the family's daily schedule. The research showed that the majority of respondents watch television on a daily basis (Table 1).

Table 1. Frequency of watching television per week

\begin{tabular}{|c|c|c|c|}
\hline 1. & $\begin{array}{l}\text { How often a week do you } \\
\text { usually watch television? }\end{array}$ & Frequency & Percentage \\
\hline 1 & Everyday & 782 & $77.9 \%$ \\
\hline 2 & 2 to 4 times a week & 180 & $17.9 \%$ \\
\hline 3 & Once a week & 42 & $4.2 \%$ \\
\hline & Total & 1004 & $100.0 \%$ \\
\hline \multicolumn{4}{|c|}{$\chi 2=925.347 \quad \mathrm{df}=2 \quad \mathrm{p}=0.000$} \\
\hline \multicolumn{4}{|c|}{$\begin{array}{l}\text { Hi-square is statistically significant and the subjects } \\
\text { most often answer: Everyday, to the question asked: } \\
\text { How often during the week they usually watch television }\end{array}$} \\
\hline
\end{tabular}

The research also showed that slightly more than half of the respondents watch television for one to three hours a day (Table 2). 
Table 2. Frequency of watching television on a daily basis

\begin{tabular}{|c|l|c|c|}
\hline 2. & $\begin{array}{l}\text { How long a day do you } \\
\text { watch television? }\end{array}$ & Frequency & Percentage \\
\hline 1 & No answer & 2 & $.2 \%$ \\
\hline 2 & Up to 1 hour & 269 & $26.8 \%$ \\
\hline 3 & From 1 to 3 hours & 556 & $55.4 \%$ \\
\hline 4 & More than 3 hours & 177 & $17.6 \%$ \\
\hline & Total & $\mathbf{1 0 0 4}$ & $\mathbf{1 0 0 . 0} \%$ \\
\cline { 2 - 4 } & $\chi 2=640.741 \mathrm{df}=3$ & $\mathrm{p}=0.000$ \\
\hline
\end{tabular}

The obtained Hi-square is statistically significant. The subjects most often answer: from 1 to 3 hours to the question asked: How long a day they watch television.

The general conclusions are: 1 . on an annual basis, adolescents spend more time watching television than they spend on any other activity; 2 . until they reach adulthood, they spend significantly more time watching television than at school, with teachers, friends or family. "The time they characterized as their leisure time, young people spend in front of the $\mathrm{TV}$, which they perceive of as a non-existent interlocutor, providing them with the contents that interests them" [14]. Numerous previous research studies have completely confirmed the presented results, which raises the essential question of the given context. Who creates paradigms? Who educates, who educates generations? Is it a family, school, or role models we are proud of? Are the young educated by those we are convinced they should be, or entirely by someone else? Almost imperceptibly, through the effect of the "cooked frog", the roles were completely switched, and only irrationality and superficiality remained between the truth and us. The family is educating less and less, the school does not even manage to correct the curved media generated matrices, let alone educate the young, and the role models are no longer something to be proud of but quite on the contrary. All those who had key positions in growing up were replaced by media, in "their own way". A way that does not imply upbringing, education and development of potentials, but mere programming. If programming is a method, dumbing down, fooling around, blunting, and going crazy are appropriate techniques. Therefore, it should come as no surprise that most respondents do not even see how obsessed they are with television, and that they think they spend exactly as much time as necessary with television (Table 3).
Table 3. Opinion on the time spent with television

\begin{tabular}{|c|c|c|c|}
\hline 3. & $\begin{array}{l}\text { Do you think it is too } \\
\text { much time: }\end{array}$ & Frequency & Percentage \\
\hline 1 & No answer & 2 & $.2 \%$ \\
\hline 2 & Too much time & 185 & $18.4 \%$ \\
\hline 3 & Exactly as much as needed & 751 & $74.8 \%$ \\
\hline 4 & Insufficient time & 66 & $6.6 \%$ \\
\hline & Total & 1004 & $100.0 \%$ \\
\hline \multicolumn{4}{|c|}{$\chi 2=1396.741 \quad \mathrm{df}=3 \quad \mathrm{p}=0.000$} \\
\hline \multicolumn{4}{|c|}{$\begin{array}{l}\text { Hi-square is statistically significant and the subjects } \\
\text { most often answer: Exactly as much as needed } \\
\text { The obtained result is not an objective criterion, but } \\
\text { the self-assessment of the subjects }\end{array}$} \\
\hline
\end{tabular}

As with the results with the use of television, the largest number of respondents use the Internet on a daily basis (Table 4).

\section{Table 4. Frequency of Internet use per week}

\begin{tabular}{|c|l|c|c|}
\hline 4. & $\begin{array}{l}\text { How often during a week } \\
\text { do you use Internet? }\end{array}$ & Frequency & Percentage \\
\hline 1 & No answer & 5 & $.5 \%$ \\
\hline 2 & Everyday & 765 & $76.2 \%$ \\
\hline 3 & 2 to 4 times a week & 153 & $15.2 \%$ \\
\hline 4 & Once a week & 81 & $8.1 \%$ \\
\hline \multicolumn{2}{|c|}{$\chi^{2}=1447.076 \quad \mathrm{df}=3$} & $\mathrm{p}=0.000$ \\
\cline { 2 - 4 } & Total & 1004 & $100.0 \%$ \\
\hline
\end{tabular}

Hi-square is statistically significant and the subjects most often answer: Everyday to the question asked:

How often during a week do you use Internet. It is interesting that $2 \%$ of respondents did not answer the question because they do not have access to the Internet, which they wrote on the margins of the questionnaire. These are the students of the elementary school "Lela Popović" from Miljkovac

"The variety of mobile devices that allow children to remain connected at all times, and across all physical spaces, means that virtual-social world is ever present, and is just as dominant and central to children's lives as the concrete reality within which they live" [6].

When it comes to everyday use of the Internet, approximately identical number of respondents indicate that they use the Internet for one to three hours and more than three hours every day (Table 5). 
Table 5. Frequency of daily Internet use

\begin{tabular}{|c|c|c|c|}
\hline 5. & $\begin{array}{l}\text { How long a day do you spend } \\
\text { on the Internet? }\end{array}$ & Frequency & Percentage \\
\hline 1 & No answer & 7 & $.7 \%$ \\
\hline 2 & Up to 1 hour & 234 & $23.3 \%$ \\
\hline 3 & From 1 to 3 hours & 385 & $38.3 \%$ \\
\hline 4 & More than 3 hours & 378 & $37.6 \%$ \\
\hline & Total & 1004 & $100.0 \%$ \\
\hline
\end{tabular}

The obtained Hi-square is statistically significant and the subjects most often answer: From 1 to 3 hours, to the question asked: How long a day do you spend on the Internet?

The obtained results explicitly indicate that young people watch television and access the Internet every day (Table 2, Table 5). There are also some discrepancies in the data on the time format, that is the number of hours spent with offline and online media. Due to the comparative analysis of the given level, the binary variable should be compared separately.

Table 6. Comparative analysis of time spent on the Internet and with television on a daily basis

\begin{tabular}{|l|l|l|l|}
\hline & $\begin{array}{l}\text { Comparative tabular } \\
\text { presentation of the answer to } \\
\text { the question: How many hours } \\
\text { a day do young people spend } \\
\text { watching television and the } \\
\text { Internet? }\end{array}$ & Television & Internet \\
\hline 1 & No answer & $27 \%$ & $23 \%$ \\
\hline 2 & Up to 1 hour & $55 \%$ & $38 \%$ \\
\hline 3 & From 1 to 3 hours & $18 \%$ & $38 \%$ \\
\hline 4 & More than 3 hours & $1 \%$ \\
\hline
\end{tabular}

By comparing the obtained data, a certain advantage of the Internet use was revealed, when it comes to a time period longer than three hours, which the subjects spend networked (Table 6). On the other hand, $55 \%$ of the sample wathes television program contents, between one and three hours, every day (Table 6). Finally, and despite the extremely high prevalence of IT technologies, the television media continues to "occupy" most of the subjects' leisure time.
When it comes to the time quantity of internet use, slightly more than half of the respondents think, as with the question for television, to use it as much as necessary (Table 7).

Table 7. Respondents' opinion on the amount of time spent with Internet

\begin{tabular}{|c|l|c|c|}
\hline 7. & Do yo think it is much time: & Frequency & Percentage \\
\hline 1 & No answer & 7 & $.7 \%$ \\
\hline 2 & Much time & 331 & $33.0 \%$ \\
\hline 3 & Exactly as much as needed & 518 & $51.6 \%$ \\
\hline 4 & Insufficien time & 148 & $14.7 \%$ \\
\hline \multicolumn{2}{|c|}{ Total } & $\mathbf{1 0 0 4}$ & $\mathbf{1 0 0 . 0 \%}$ \\
\cline { 2 - 4 } & \multicolumn{2}{|c|}{$\mathrm{d}=588.980 \mathrm{df}=3$} & $\mathrm{p}=0.000$ \\
\hline
\end{tabular}

The obtained Hi-square is statistically significant and the subjects most often answer: Exactly as much as needed. The obtained result is not an objective criterion, but the self-assessment of the subjects

\subsection{Persistence and Multivariance of the Persuasive Media Properties}

The advertising industry belongs to a group of the most profitable industries, according to the consumer spectrum, and it is a specific form of persuasion, based on precisely designed attempts to influence: attitudes, values, emotions, beliefs, in a word behavior. The advertising industry is actually an industry of ideology, an industry of behavior, programmed through the mass media. The desirable outcome of the analysis of the obtained data should be: more complete knowledge about the impact of television advertising on the behavior of adolescents, including consumer motivation and the the impact of commercial culture on consumer habits (Table 8, Table 9).

Table 8. Interest in commercial program

\begin{tabular}{|c|l|c|c|}
\hline 8. & Do you watch commercials? & Frequency & Percentage \\
\hline 1 & No answer & 28 & $2.8 \%$ \\
\hline 2 & Yes, gladly & 55 & $5.5 \%$ \\
\hline 3 & Sometimes & 479 & $47.7 \%$ \\
\hline 4 & $\begin{array}{l}\text { No, I always change the TV } \\
\text { program }\end{array}$ & 442 & $44.0 \%$ \\
\hline \multicolumn{2}{|c|}{ Total } & $\mathbf{1 0 0 4}$ & $\mathbf{1 0 0 . 0 \%}$ \\
\cline { 2 - 4 } & \multicolumn{2}{|r}{}
\end{tabular}

Hi-square is statistically significant, $47,7 \%$ subjects answers with: Sometimes to the question asked: Do you watch commercials? Only: 37 subjects less, therefore: 442 pupils responded that they do not watch commercials 
Table 9. The influence of advertising on the choice of purchase

\begin{tabular}{|c|c|c|c|}
\hline 9. & $\begin{array}{l}\text { To what extent do } \\
\text { commercials influence } \\
\text { your shopping choices? }\end{array}$ & Frequency & Percentage \\
\hline 1 & No answer & 18 & $1.8 \%$ \\
\hline 2 & To a great extent & 65 & $6.5 \%$ \\
\hline 3 & To some extent & 365 & $36.4 \%$ \\
\hline 4 & $\begin{array}{l}\text { They do not extent } \\
\text { influence }\end{array}$ & 556 & $55.4 \%$ \\
\hline & Total & 1004 & $100.0 \%$ \\
\hline \multicolumn{4}{|c|}{$\chi 2=776.518 \quad \mathrm{df}=3 \quad \mathrm{p}=0.000$} \\
\hline \multicolumn{4}{|c|}{$\begin{array}{l}\text { Hi-square is statistically significant and the subjects } \\
\text { mostly answer with: They do not exert influence } \\
\text { to the question asked: To what extent do commercials } \\
\text { influence your shopping choices? }\end{array}$} \\
\hline
\end{tabular}

The scope, intensity and types of influences, as well as the persistence and multivariate effects of advertising media contents on children and adolescents, are current topics of numerous research studies. More or less successfully, the common denominator of findings directly indicates consciousness programming. However, this is all about explicit advertising contents, which are mostly very aggressive and the intensive repetition formatted, and as such are therefore "boring" to the adolescent population. However, media users are inundated with "in place" marketing, i.e. hidden forms of advertising, which is especially the case of the e-environment media. Classic commercials, according to the results, may not influence the choice to the expected extent, but by broadcasting the shows: "how they live, what celebrities buy or use", "reality program contents" or "reality reports on peer habits in the market-oriented systems", strong influence exertion on the "choice" of the subjects is no longer disputable. However, although slightly more than half of the respondents point out that commercials do not influence their choice when buying, a third of respondents state that advertisements somewhat influence their choice (Table 9).

The "market" dictates a way of life for young people, developing hedonistic tendencies and the ultimate orientation towards the material values. The methodology is mostly recognizable in the programming of pseudo-values and quasi-needs. Adolescents are an "army" of potential mass consumers, on whom the volume and intensity of consumption will soon depend. Therefore, they should be prepared in time, until the value systems are not more firmly established, first of all by directing value orientations. At the same time, the discussions about the violation of the elementary rights are completely pointless because the main concern here is about survival: of "the way of life", and even more importantly, of "the way of production". The initial considerations of the research results in question could be somewhat encouraging, because the obtained data are only seemingly in contradiction with the presented conclusions. Until when will the expressed restraint survive as an important category, or up to which point of development will the colorful and well-lit consumer scene take precedence and overshadow all other values. In adolescence, exposure to media influences may be sufficient, regardless of the effect, because they will later impose as a common environment, long internalized in consciousness, as a code or the only value, that is, as a necessity.

\section{Concluding Remarks}

The vicious developmental circle allowing for the society survival reminds us only that poverty is not a state of an estimation, but the state of consciousness. The economic power of the society significantly puts constraints to all types of offers, including media offer, and a weak family strength addidtionally narrows the choice down, in the same way as is the possibility of participation in the offered contents. Proper development of the appropriate value orientation of the young people by avoiding idleness, apathy, risky behaviors and demotivation, is a priority of the strategy, which emphasizes foremost a development of the personal potentials, and a planned approach to the key problems of a given domain. Thereby, the media contents should also be made more accessible, and users should be, in an inventive way, directed towards participation in social life, with acceptance and respect of elementary values.

\subsection{Circulus Vitiosus}

The trend of decomposing already established value systems has been intensified, and manipulation techniques are becoming increasingly complex. By analyzing the results of this research, it has also been explicitly pointed to the scope, quality and the intensity of media paradigms. Consequences produced by media contents in the minds of the young people cannot be annuled by any formal education system. Even if we had goodwill, time, resources, great programs and even better staff, it woud be and it is already too late now. Cognitive patterns, as well as a good deal of value orientations, have already been established even before the child starts attending prep-schools. On the other hand, media education has been imposed as a necessary part of the formal system, as an instrument and 
method of prevention, that is, a "defense mechanism" or, at first, as a way of even recognizing a problem. At he same time, results in a given field cannot be expressed quickly even if the problems are treated by the best designed systems, because the most attractive media, precisely those that make the largest amount of profit, should be systematically "filtered" and polished to the level of concepts that places media influence in the function of the social development. In that kind of process, adolescents either should not be passive observers, because media are supposed to serve us, and we are not to serve them. In other words, it is delusive to talk about media freedom, without the freedom for all of us, and without the freedom of all mass communication actors. A metamorphosis of the approach model of understanding would also be desirable to begin with. Are we born for the media or are the media created for us? Are we born as consumers? Are we dedicated to consumption, or are the goods intended to meet oour needs? It is of high importance to establish a critical attitude towards everything, and nowadays media are the "window" into everything that surrounds us. Without critical thinking and an independent "production" of information, in a tested process implying that we assign meaning to the data ourselves, the brain could undergo atrophy. Then, the negative influences of the media would completely dominate, and manipulation would become a dominant instrument of communication at all levels. There are so many examples that sometimes it is hard to believe in the truth of obvious. Have we been creating and perfecting the writing scripts for millennia only to, in a few decades with media, start again to write and talk?

\subsection{The Ultimate Media Messages and Decomposition of the Value System}

Modern media paradigms by conveying new media messages definitely promote competences over competitions, diminish codes of values and constantly blur the border line between the good and bad, animal and humanistic. The numerous forms of manipulative media features tackling human mind are getting more sophisticated, more dynamic, natural and tougher. Is it just the novelty of modern vanity, or the reincarnation of the ancient mythology?

The crucial influence of the media on the formation of attitudes and the value orientation of the adolescents, whether positive or negative, has been confirmed by this research. However, there was also a noticeable shift in the correlative relationship between media contents and the interests of the young people, since the central programmatic positions of media, as dictated, are both represented and positioned in the interests of the subjects. For example, if the focus of media values is on knowledge, education, respect, work, responsibility, honest relationship, assertive communication, tradition, culture or science, then the media also enter the field of the youth education in a way that is appropriate to developmental needs. On the other hand, if media messages are full of depictions of the "vip" personalities, illiterate or semi-literate statements by the representatives of the "elite" and paradigms such as: false representations of the "glory", dazzling success accomplished "overnight", aggressive communication, glorification of power and violence, popularization of idleness, manipulation of simplicity, promotion of the consumer mentality up to the level of meaninglessness, arrogance, hate speech or incitement rhetoric, all of these exert, not at all small influence of the media, on a completely different plane. This is the plane of decomposition, destruction and senselessness, that is, retrograde decomposition of the value system. 


\section{References}

[1]. Castells, M. (2013). Communication power. OUP Oxford.

[2]. Džajls, D. (2011). Psihologija medija. Beograd: Clio. (page 94)

[3]. Drotner, K., \& Livingstone, S. (Eds.). (2008). International handbook of children, media and culture. Sage.

[4]. Foa, M. (2017). Gospodari medija. Beograd: Clio.

[5]. Livingstone, S. (2016). Reframing media effects in terms of children's rights in the digital age. Journal of children and media, 10(1), 4-12.

[6]. Lemish, D. (2015). Children and media: A global perspective. John Wiley \& Sons.

[7]. Maksimović, J., \& Stanisavljević Petrović, Z. (2014). Teorijsko-metodološka zasnovanost istraživanja utjecaja medija na adolescente. In medias res: časopis filozofije medija, 3(4), 472-486.

[8]. Perišin, T. (2008). Televizijske vijesti: u potrazi za vrijednostima. Medijska istraživanja, 14(2), 63-86.

[9]. Prajs, S. (2011). Izučavanje medija. Beograd: Clio. [10]. Radok, E. (2015). Mladi i mediji. Clio, Beograd.
[11]. Radović, V. (2006). Mediji i e-obrazovanje. Institut za političke studije.

[12]. Rejk, B., Edkok, K., \& Popović, T. (1978). Vrednosti, stavovi $i$ promena ponašanja. Nolit.

[13]. Stanisavljević-Petrović, Z., Radović, V., \& Ivanović, A. (2012). Media literacy and culture of the primary school pupils in Niš. Kultura, (137), 210-234.

[14]. Valić Nedeljković, D. (2012). Deca i mediji obraćamo li dovoljno pažnje? Link, časopis za profesionalce $u$ medijima, Novi Sad: Media Art Service International, (broj 105, godina XI), (page 89).

[15]. Valić Nedeljković, D., Bala, K., \& Geler, Z. (2013). Deca $\mathrm{u}$ virtuelnom svetu kompjuterskih igrica, $\mathrm{u}$ Digitalne medijske tehnologije i društveno-obrazovne promene 3, ur. D. Valić Nedeljković\& D. Pralica (Novi Sad: Filozofski fakultet), 241-254.

[16]. UNICEF (2010). Deca u medijskom ogledalu: Predstave o deci u informativnim medijima u Srbiji. Beograd: Dečiji fond Ujedinjenih nacija. Retrieved from: https://www.unicef.org/serbia/publikacije/deca-umedijskom-ogledalu [accessed: 10 December 2020]. 